\title{
Caracterização dos recursos hídricos do município de Conceição - PB: as políticas de acesso à água
}

\author{
Characterization of water resources in the municipality of Conceição - PB: water access \\ policies.
}

\author{
LIMA $^{1}$, K.C.L.S.; LIMA ${ }^{2}$,V.F.; FRANCO ${ }^{3}$, V.V.; MARTINS ${ }^{4}$,V.V.; RAMOS ${ }^{5}$, L.U. F. \\ kayocesar.lima@outlook.com
}

\begin{abstract}
Resumo
Historicamente a disponibilidade, uso e gestão dos recursos hídricos no semiárido nordestino se configuram como a maior privação no que se refere ao seu desenvolvimento. É fato notório que algumas medidas vêm sendo implantadas visando minimizar os efeitos das longas estiagens no semiárido. Entre as medidas mais expressivas estão a criação e implantação de infraestruturas ou novas tecnologias sociais hídricas. Esta pesquisa preliminar tem como principal objetivo realizar uma caracterização dos recursos hídricos do município de Conceição, localizado na Mesorregião do Sertão Paraibano e na Microrregião de Itaporanga no alto sertão paraibano, utilizando como base para análise um banco de dados georreferenciados de todas as pequenas obras hídricas do município, para verificar a potencialidade de armazenamento dessas pequenas obras e compará-las com os grandes reservatórios que abastecem este município. Os resultados obtidos podem vir a colaborar com o melhor conhecimento das pequenas obras hídricas no que se refere principalmente a sua localização precisa e seu potencial de armazenamento, podendo com isso contribuir para uma melhor gestão das águas, visto que esse problema toma corpo cada vez mais no semiárido nordestino.
\end{abstract}

Palavras-chave: Diagnóstico hídrico; Gestão de águas; Tecnologias Sociais Hídricas.

\begin{abstract}
Historically the availability, use and management of water resources in semiarid northeast are configured as the greatest deprivation in relation to its development. It is well known that some measures have been implemented to minimize the effects of the long drought in the semiarid region, among the most significant measures are the creation and implementation of new infrastructure or water social technologies. This preliminary research is aimed at providing a characterization of water resources in the municipality of Conceição, located in mesoregion of Paraiba's Sertão and the microregion of Itaporanga in Paraiba's Alto Sertão, using as a basis for the analysis a georeferenced database of all small water constructions of the municipality in order to check the storage capability of these small cnstructions and compare them with the large reservoirs that supply the municipality. The results are likely to collaborate with the best knowledge of small hydric constructions in mainly refers to its precise location and their storage potential, and this may contribute to improve water management, given that this problem takes shape increasingly in semiarid northeast.
\end{abstract}

Keywords: water diagnosis; water management; water social technologies.

\section{INTRODUÇÃO}

As características pedológicas, litológicas, climáticas e também socioeconômicas do semiárido brasileiro, aqui em destaque o sertão paraibano, dão a essa região atributos não favoráveis ao desenvolvimento, visto a sua indisponibilidade hídrica. Por tanto essas áreas carecem imediatamente de intervenções e politicas publicas atualmente chamadas de tecnologias sociais, que garantam a utilização, conservação e gestão dos recursos hídricos.

De acordo com Ab'Saber (2003), no semiárido nordestino, as chuvas ocorrem de maneira irregular com 400 a $800 \mathrm{~mm}$ anuais em média. Estes níveis pluviométricos são expressivos se

\footnotetext{
${ }^{1}$ Kayo César Lacerda de Sousa Lima, Departamento de Engenharia Civil e Ambiental, Universidade Federal da Paraiba, PB, Brasil

${ }^{2}$ Vinicius Ferreira de Lima, Centro de Ciências Exatas e da Natureza/LEGAM,Universidade Federal da Paraiba, PB, Brasil

${ }^{3}$ Virna Vieira Franco, Centro de Ciências Exatas e da Natureza,Universidade Federal da Paraiba, PB, Brasil

${ }^{4}$ Vinicius Vieira Martins, Centro de Humanidades,Universidade Estadual da Paraiba, PB, Brasil

${ }^{5}$ Lawdson Ueslley Firmino Ramos, Centro de Ciências Exatas e da Natureza,Universidade Federal da Paraiba, PB, Brasil
} 
comparados a outras regiões semiáridas do mundo, porém, estas são extremamente concentradas, acarretando longos períodos de estiagem.

$\mathrm{Na}$ raiz do problema, além do quadro de escassez, a utilização indevida e incorreta dos recursos hídricos aumenta consideravelmente a fragilidade da região ao processo de desertificação, tomando assim proporções de diferentes escalas, seja ao que tange o consumo dos recursos hídricos pelas populações ocupantes desse território, ou no que se remete ao processo de ampliação da produção agrícola e industrial.

O município de Conceição, localizado no Sertão da Paraíba, apresenta em seu território algumas tecnologias que tentam garantir a segurança hídrica do município. Entre elas está a construção de dois grandes reservatórios artificiais localmente chamadas de açudes, um desses reservatórios o açude da Ladeira tem por finalidade garantir o abastecimento urbano do município, o outro o açude do Condado tem na matriz inicial do projeto perenizar o leito do Rio Piancó para possibilitar a manutenção de agriculturas irrigáveis para os pequenos agricultores situados próximos as margens do rio. Entretanto, os resultados obtidos ficaram muito a baixo das expectativas, principalmente no segundo caso, pois não houve uma gestão eficiente destes corpos hídricos, os problemas persistiram e a vida pouco mudou para os pequenos agricultores que estão a jusante do rio e principalmente para as populações rurais que se localizam distante das margens do rio Piancó.

Tendo em vista que estas obras supracitadas foram insuficientes para o desenvolvimento social e econômico e para a permanência de parte da população principalmente rural no município, faz-se necessário abordar o problema de escassez de água e abastecimento a comunidades que não são beneficiadas, levando em consideração tecnologias alternativas, de baixo custo e fácil apropriação pela população. Pesquisas atuais como (VIANNA, et. al, 2013; ARAÚJO 2011; SEUNDO NETO et. al, 2013) revelam que tecnologias que tem apresentado bons resultados contra a seca, por seu baixo custo e fácil acesso a comunidade, denominadas de Tecnologias Sociais Hídricas, fazendo parte destas: cisternas de placa, cisterna calçadão, barragem subterrânea e poços rasos, entre outras. De acordo com os mesmos autores, essas obras hídricas de pequeno porte possibilitam o armazenamento de água doce em uma escala adequada às unidades familiares, criando uma relação de sustentabilidade.

Este trabalho tem como objetivo primordial realizar um diagnóstico dos recursos hídricos utilizando um banco de dados georreferenciados de todas as pequenas obras hídricas (cisternas de placa, cisternas calçadão e poços tubulares) do município de Conceição - PB, para analisar a potencialidade de armazenamento dessas pequenas obras e compará-las com os grandes reservatórios que abastecem este município. 
O banco de dados georreferenciado foi fornecido pelo Laboratório de Estudos de Gestão de Água e Território - LEGAT da Universidade Federal da Paraíba. A eficácia dessas tecnologias sociais hídricas de pequeno porte no semiárido paraibano vem sendo objeto de estudo desse laboratório, atestando a eficiência da construção de um Sistema de Informação Geográfica - SIG para o diagnostico dos recursos hídricos municipais.

O município de Conceição ocupa uma área aproximada de $577,6 \mathrm{~km}^{2}$, está localizado na região oeste do estado da Paraíba na microrregião de Itaporanga, limitando-se a leste com Santana de Mangueira e Ibiará, a norte Bonito de Santa Fé, a nordeste São José de Caiana e Diamante, a oeste com Mauriti no Ceará e a sul Santa Inês (Figura 1).

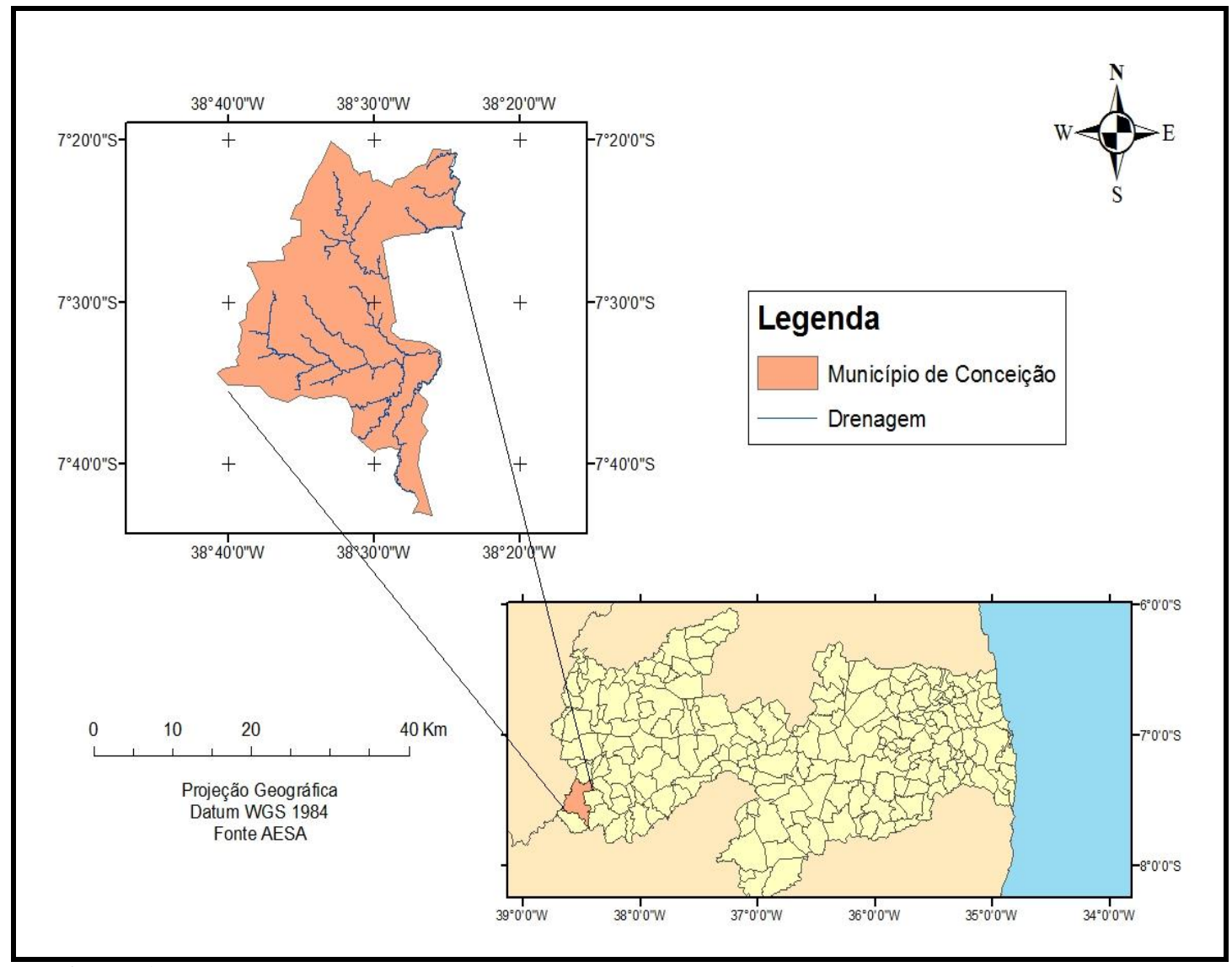

Figura 1: Localização do município de Conceição - PB Fonte: Elaboração Própria do autor (2016).

Segundo o (IBGE, 2010) O município de Conceição possui 18.363 habitantes. Em termos climatológicos o município acha-se inserido no denominado "Polígono das Secas", constituindo um tipo semiárido quente e seco. As temperaturas são elevadas durante o dia, amenizando a noite, com variações anuais dentro de um intervalo 23 a $30^{\circ} \mathrm{C}$, com ocasionais picos mais elevados, principalmente durante a estação seca. O regime pluviométrico, além de baixo é irregular com média anual de 862,6mm/ano e valores mínimo e máximo de 346,8 e 1750,3 mm/ano respectivamente (BRASIL, 2005). Os solos são resultantes da desagregação e decomposição das 
rochas cristalinas do embasamento, tendo com isso solos pouco espessos e com difícil infiltração das águas.

\section{METODOLOGIA}

A primeira etapa para efetivação da pesquisa consistiu na revisão bibliográfica e no levantamento de dados e materiais disponíveis sobre a região e adjacências, em particular todo o semiárido paraibano, e mais precisamente, sobre a área de estudo. Foram levantados os seguintes materiais e dados:

-Censo demográfico 2010 do município de Conceição;

-Banco de dados com informações referentes aos corpos hídricos (artificiais e naturais) e cisternas de placas, fornecidos pelo Laboratório e Estudos de Gestão de Água e Território (LEGAT);

-Dissertações de Mestrado, Teses de Doutorado sobre a região além de artigos em revistas e periódicos e trabalhos monográficos;

-Mapa Geológico do Estado da Paraíba e texto explicativo (Brasil, 2002);

-Mapa Pedológico do Estado da Paraíba e texto explicativo (Paraíba, 2004);

-Dados climáticos.

O mapeamento das obras hídricas foi realizado por meio de imagens de satélites disponíveis no software gratuito Google Earth para identificar os corpos de armazenamento de água, sejam eles naturais ou artificiais (Figuras 2 e 3). Em seguida foram inseridas informações a respeito de volume, capacidade, perímetro e área dos reservatórios.

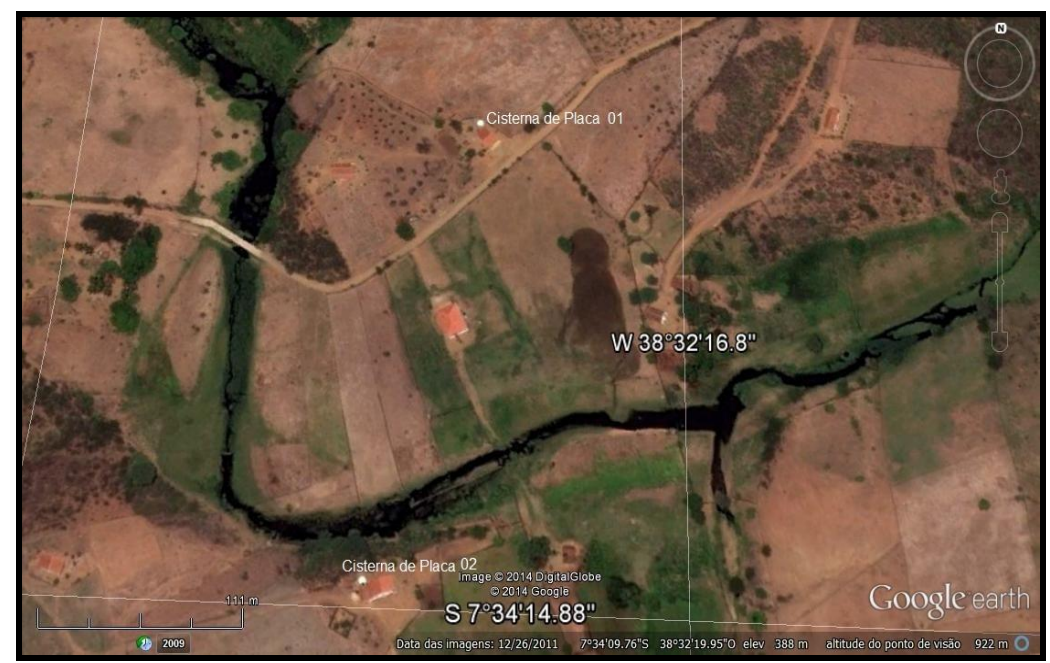

Figura 2: Imagem do Google Earth de identificação das cisternas de placas. 


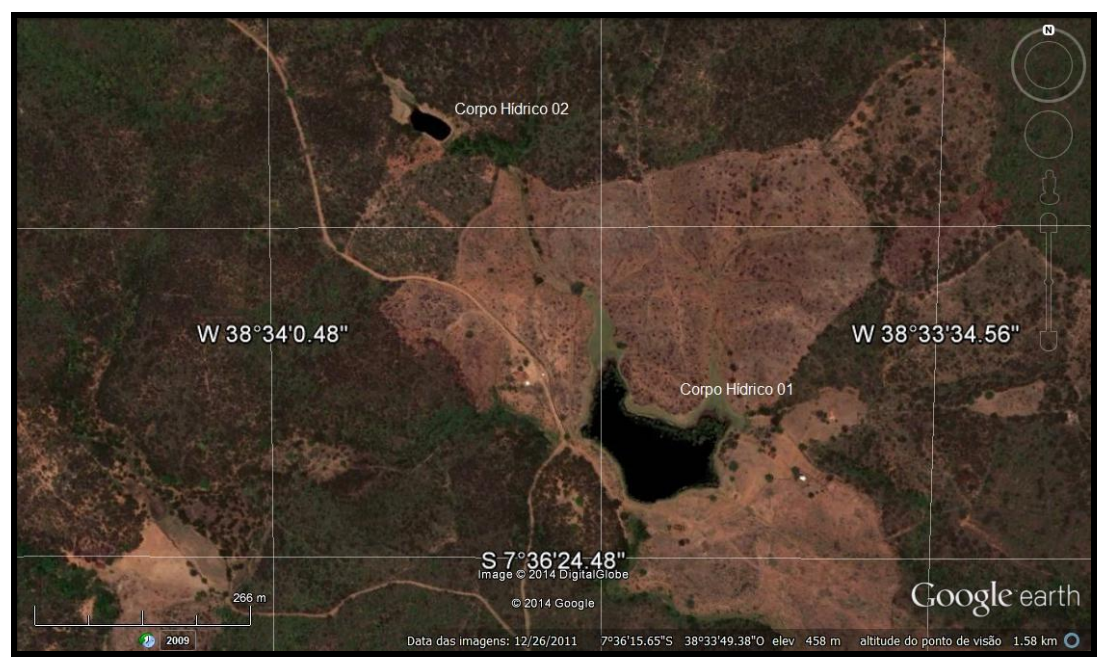

Figura 3: Imagem do Google Earth de identificação dos corpos hídricos.

A segunda etapa já com o mapa de distribuição espacial dos recursos hídricos em mãos, e com ajuda de imagens de satélite, foram traçados os principais pontos de estudos de campo, que foram os pontos referentes às áreas de maior disponibilidade dessas tecnologias sociais, assim como também, as áreas com maior carência hídrica. O trabalho de campo foi realizado, com os materiais cartográficos em mãos, ficha para entrevistar alguns moradores que se utilizam dessas pequenas obras hídricas, câmera fotográfica e aparelho de GPS (Global Position System).

\section{RESULTADOS E DISCUSSÃO}

As águas superficiais do município de Conceição estão distribuídas principalmente nos dois principais reservatórios artificiais, que são o açude do Condado e o açude da Ladeira e os córregos fluviais de regime intermitente. O município encontra-se inserido nos domínios da bacia hidrográfica do Rio Piranhas, sub-bacia do Rio Piancó sendo este periodicamente perenizado pelo solte de água do Açude do Condado. Os principais cursos de água são: o Rio Piancó e os riachos: Coelho, Humaitá, do Catolé, do Barro Vermelho, do Criminoso, do Poço Redondo, da Posse, das Canas, das Cabaças e Papa Mel. Como já mencionado, todos os cursos de água têm regime de escoamento intermitente.

A bacia hidrográfica do Rio Piancó que corta o município de Conceição e está inserido no projeto de bacias receptoras das águas do São Francisco do eixo norte. O Projeto de Integração do Rio São Francisco (PISF) com as Bacias Hidrográficas do Nordeste Setentrional é uma grande obra de aporte hídrico, que tem por objetivo assegurar a demanda de água para a região que mais sofre com a irregularidade das chuvas e com prolongados períodos de escassez (SEGUNDO NETO, 2014). 
Conforme os dados analisados, o município de Conceição apresenta em seu território 484 corpos hídricos no total, configurando-se em sua maior parte como artificiais, dos quais apenas 3 são monitorados pela Agência Executiva de Gestão das Águas do Estado da Paraíba (AESA) que são o Açude do Condado, o Açude da Ladeira e o Açude Video. Esses monitoramentos visão medir a qualidade das águas superficiais para o consumo humano, e enquadrou o município na faixa de água regular, de pequenas a médias restrições ao consumo humano. Estatisticamente as pequenas obras hídricas somam um número de 281 obras, sendo que 204 são cisternas de placa que tem por finalidade abastecer as famílias no período de estiagem e 77 são os poços (Figura 4).

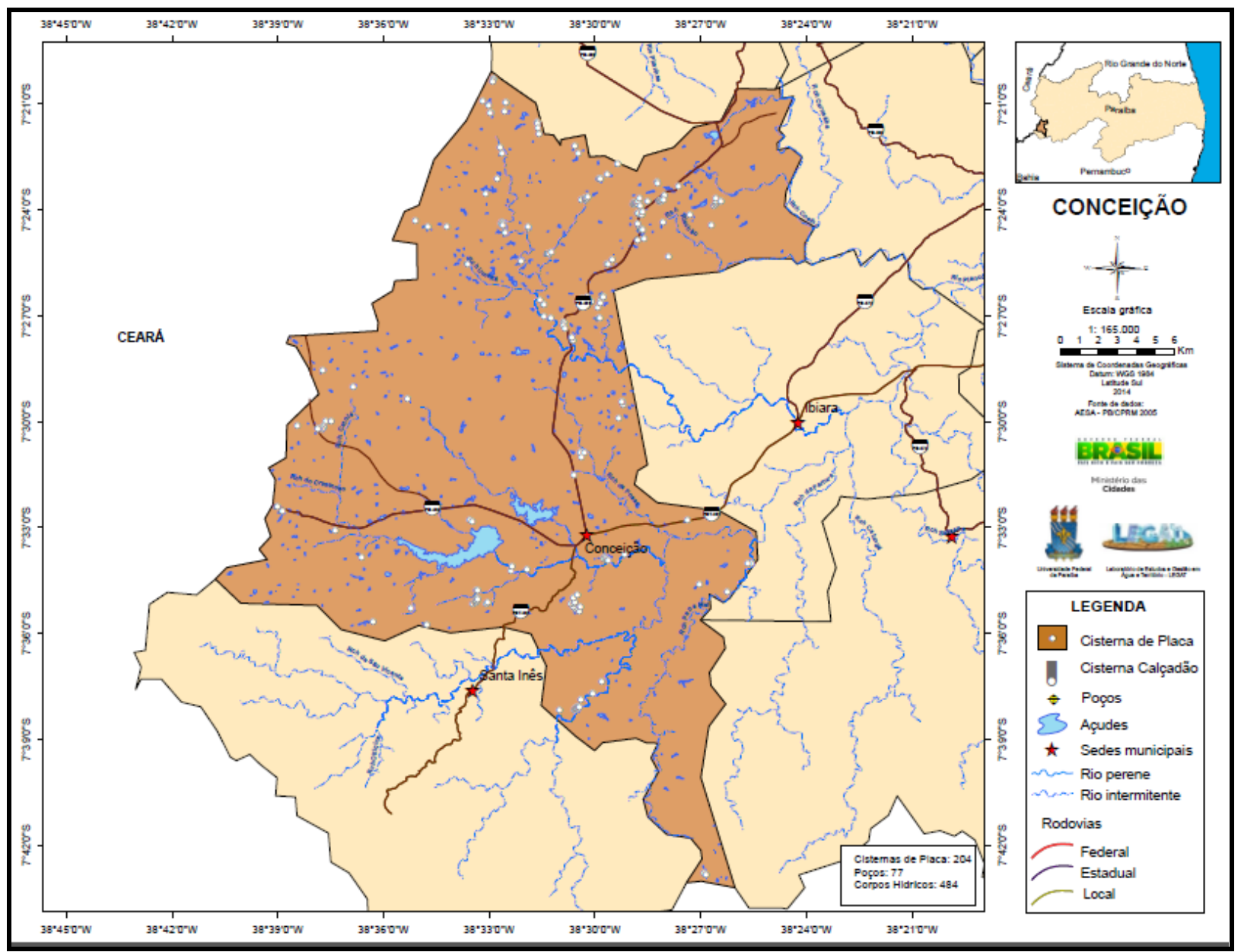

Figura 4: Mapa da distribuição das cisternas de placa e dos corpos hídricos no município de Conceição - PB. Fonte: Laboratório e Estudos de Gestão de Água e Território (LEGAT).

O Açude do Condado que entre outras coisas tem por finalidade a perenização do Rio Piancó que deveria ser utilizado para incentivar o pequeno irrigante a produzir alimento, apresenta uma capacidade máxima de $35.016 .000 \mathrm{~m}^{3}$, porém, atualmente possui um volume de $6.393 .400 \mathrm{~m}^{3}$ que corresponde apenas há $18,3 \%$ de sua capacidade total. O Açude da Ladeira tem uma capacidade total de $11.801 .173 \mathrm{~m}^{3}$ e atualmente apresenta um volume de $129.849 \mathrm{~m}^{3}$ o que corresponde em porcentagem há $1,1 \%$ de sua capacidade máxima, este é o responsável pelo abastecimento do 
município, enquanto que o Açude Video tem uma capacidade máxima de 6.040.264 $\mathrm{m}^{3}$, apresentando atualmente apenas 7,5\% da sua capacidade máxima.

Utilizando o SIG e o banco de dados georreferenciados fornecidos pelo (LEGAT) que nos dão informações precisas referentes a quantidade e localização dos corpos hídricos, podemos ter um diagnóstico quantitativo da capacidade de armazenamento do município, somando a capacidade de armazenamento total das cisternas de placa, já que sabemos que quando cheias armazena um total de 16.000 litros de água, temos por tanto com a somatória de 204 cisternas uma quantidade média de 3.264.000 litros no município de Conceição. Um dado importante a ser mencionado é que as cisternas de placa em sua grande maioria estão inseridas na área rural do município, visto que essa população é a que mais apresenta carência de água para o próprio consumo. Consultando os dados do Censo 2010, a população rural do município de Conceição é de 6.930 habitantes, o que representaria deste total hídrico das cisternas, uma média de 471 litros por habitante.

Alguns dados levantados atualmente pelo Laboratório e Estudos de Gestão de Água e Território (LEGAT) em outros municípios na região semiárida do mesmo Estado da Paraíba, mostram que em 5 municípios da zona do Cariri Paraibano as cisternas abastecem mais de 50\% da população rural e em 19 deles o sistema das Tecnologias Sociais Hídricas conseguem atingir mais de $20 \%$ da população rural (VIANNA et. al, 2013). No caso particular do município de Conceição, considerando que uma cisterna abasteça uma família de 5 pessoas no período de estiagem, 15\% da população rural é beneficiada por essas obras hídricas de pequeno porte no município.

Referente aos poços, podemos verificar que são encontrados em média 77 poços tabulares no município, sendo que segundo o levantamento realizado pela SPRM em 2005, a grande maioria desses poços são privados e destinados ao consumo doméstico, visto que a vasão dos mesmos se configuram como insuficientes para a indústria ou para agricultura. Não sabemos os dados totais da vasão de todos os poços, pois nenhum destes reservatórios é monitorado por órgãos do governo Municipal ou Estadual, a qual não foi possível obterem-se dados. A planilha de todos os poços sua natureza e suas respectivas funções podem ser consultadas no endereço eletrônico: http://www.cprm.gov.br/rehi/atlas/paraiba/relatorios/CONC058.

A análise da espacialização e da distribuição das cisternas de placa no município de Conceição mostra uma forte ausência das cisternas nas áreas próximas aos açudes do Condado e da Ladeira e também nas áreas próximas ao leito do Rio Piancó, apresentando, no entanto, a maior concentração de poços nessa área. Essa bacia hidrográfica se configura como a de maior porte hídrico do município.

É também nas várzeas do Rio Piancó onde é intensa a presença de áreas irrigadas, mesmo que de forma inadequada para o semiárido. Como mencionado anteriormente, o Rio Piancó é 
favorecido pelo solte de água do Açude do Condado, tornando esse rio perene mesmo nos períodos de estiagem, notadamente as áreas a margem do leito desse rio se configuram como uma região favorável a agricultura principalmente de batata-doce (CORREIA, 2014).

No entanto, verifica-se atualmente a presença de conflitos geralmente envolvendo os pequenos agricultores e os órgãos governamentais que gerenciam essas águas. Algumas imposições foram estabelecidas para os pequenos irrigantes como, por exemplo, a intercalação dos dias para irrigação, impondo que os pequenos irrigantes diminuam ainda mais sua produção. Mesmo respeitando os limites atribuídos, o atual solte de água para perenização do rio, que sofreu uma considerável redução, não está sendo suficiente para a irrigação o que está tencionando ainda mais o conflito.

De certa forma, os poderes locais, estadual e federal, tendem geralmente a tentar excluir dos projetos de irrigação as populações descapitalizadas e sem nível de formação educacional, características muitas vezes apresentadas pelos pequenos produtores rurais, alegando que eles não possuem o grau exigido para dominar a técnica da irrigação e todas suas exigências. Também é de fácil percepção no município que há a construção de um espaço segregado que tem como elemento limitante a oferta hídrica. O elemento de analise também possui uma vertente temporal, pois é esperado com ansiedade pelos pequenos irrigantes que o leito do rio Piancó seja contemplado pelo projeto de transposição do rio São Francisco o que para muitos representa a solução, mas que deixa em aberto uma duvida referente ao acesso que os pequenos agricultores terão a água.

Em pesquisas futuras e apresentando um maior número de dados, pretende-se verificar o percentual de população rural que vive no entorno das margens do Rio Piancó no trecho referente ao município de Conceição e comparar estes com as populações atendidas pelas cisternas, reforçando a hipótese levantada a respeito da eficácia das tecnologias sócias hídricas nas áreas de maior carência de água.

\section{CONSIDERAÇÕES FINAIS}

A presente pesquisa utilizou-se de ferramentas de geoprocessamento utilizando o SIG e um banco de dados georreferenciados fornecidos pelo (LEGAT) para identificação, interpretação e localização de corpos hídricos, sejam eles artificiais ou naturais. Essa metodologia que vem sendo utilizada também em outros municípios do semiárido paraibano se mostrou uma importante ferramenta para a padronização e disponibilização de informação referente à capacidade hídrica municipal.

As informações e dados aqui apresentados, podem vir a contribuir com o poder municipal, podendo dar mais nitidez, eficiência e qualidade a gestão da água em situações de emergência 
hídrica. A clareza da localização precisa dos corpos hídricos e das tecnologias sócias hídricas, principalmente das cisternas de placa que mostraram nessa pesquisa que possuem um considerável porte de armazenamento podendo ser utilizada em situações emergenciais em ações que visem à amenização do estresse hídrico, tais como as distribuições de água nos caminhões pipas, comuns para períodos de estiagem nas áreas semiáridas nordestinas, minimizando com isso, os duros efeitos provocados pelas estiagens prolongadas.

Para concluir, vale lembrar que esta análise não almeja, em hipótese alguma, encerrar a questão pertinente ao estudo da área em questão e da utilização das tecnologias sociais hídricas já mencionadas, mas, sim, propiciar um meio pelo qual novos trabalhos sejam desenvolvidos na intenção de apresentar informações e dados que corroborem com os resultados aqui apresentados, permitindo, assim, o conhecimento pormenorizado da região de maneira que os processos naturais e antrópicos que comandam o quadro de escassez possam ser melhores planejados e conhecidos visando o bem comum das populações que tanto sofrem com a escassez hídrica.

\section{REFERÊNCIAS}

AB'SÁBER, A. N, Os Domínios de Natureza no Brasil: potencialidades paisagísticas. São Paulo: Ateliê Editora, 2003.

AESA - Agência Executiva de Gestão das Águas do Estado da Paraíba. Disponível em: http://www.aesa.pb.gov.br/. Acesso em 02 de Setembro de 2014.

ARAÚJO, C. F. Mapeamento das Tecnologias Sociais Hídricas nos Municípios de Juazeirinho e Soledade no Estado da Paraíba. Monografia. Graduação em Geografia - UFPB, 2011. 56p.

ARAÚJO SEGUNDO NETO, F. V. de. Análise Espacial das Obras do Projeto de Integração do Rio São Francisco (eixo leste) no Estado da Paraíba. Monografia. Graduação em Geografia UFPB, 2014. 70p.

ARAÚJO SEGUNDO NETO, F. V. de.; CUNHA, G. S.; ARAUJO, R. S.; VIANNA. P. C. G. CRIAÇÃO DE UM SIG DE PEQUENAS OBRAS HÍDRICAS PARA O DIAGNÓSTICO HÍDRICO DOS MUNICÍPIOS DE MALTA - PB E VISTA SERRANA - PB. In: VII Simpósio Nacional de Geografia Agrária, 2013, João Pessoa.

BRASIL. Ministério de Minas e Energia. CPRM. Geologia e recursos minerais do Estado da Paraíba. Recife: CPRM, 2002. 142 p. il., 2 mapas. Escala 1:500.000.

CORREIA, V. F.de L. A Problemática das Práticas Agrícolas Desenvolvidas no Sítio Maria Soares, Município de Conceição - PB. Monografia. Graduação de Licenciatura em Geografia UFCG, 2014. 90p.

CPRM - Serviço Geológico do Brasil. Diagnóstico do Município de Conceição (2005). Disponível em: http://www.cprm.gov.br/rehi/atlas/paraiba/relatorios/CONC058. Acesso em Setembro de 2014. 
IBGE. Instituto Brasileiro de Geografia e Estatística. Disponível em< http://www.ibge.gov.br/home/estatistica/populacao/censo2010/default_resultados_universo.shtm > Acesso em 12 de Setembro de 2014.

PARAÍBA. SUDEMA. Mapa pedológico do Estado da Paraíba. João Pessoa: SUDEMA, 2004. Escala: 1:500.000.

VIANNA, P. C. G.; SEGUNDO NETO, F. V. A.; CUNHA, G. S.; ALMEIDA, T. C.; LINHARES, F. M. Criação de um SIG (SGI) Para o Diagnóstico Hídrico Municipal. In: EGAL - Encontro de Geógrafos da America Latina, 2013, Lima. Anais do XIV EGAL. Lima - Peru: UGI - União Geografica Internacional, 2013.

\section{AGRADECIMENTOS}

Agradecemos em especial ao Prof. Dr. Pedro Guedes Vianna coordenador do Laboratório de Estudos de Gestão de Água e Território - LEGAT da Universidade Federal da Paraíba que nos forneceu o banco de dados georreferenciado, fundamental para o desenvolvimento dessa pesquisa.

Recebido em: 14/08/2016

Aceito para publicação em: 01/10/2016 